Deyin Gu*, Mei Ye and Zuohua Liu

\title{
Computational fluid dynamics simulation of solid- liquid suspension characteristics in a stirred tank with punched circle package impellers
}

https://doi.org/10.1515/ijcre-2020-0026

Received February 3, 2020; accepted June 20, 2020; published online August 26, 2020

\begin{abstract}
Solid-liquid suspension characteristics in a stirred tank with four pitched-blade impellers, circle package impellers, and punched circle package impellers were studied via computational fluid dynamics (CFD) simulation. A classical Eulerian-Eulerian approach coupled with the standard $k-\varepsilon$ turbulence model was adopted to simulate the solid-liquid two-phase turbulent flow. The effects of impeller speed, power consumption, impeller type, aperture size/ratio, solid particle diameter and liquid viscosity on the solid particle suspension quality were investigated. Results showed that the solid particle suspension quality was improved with an increment in the impeller speed. Punched circle package impeller could reduce the just suspension speed and improve the level of homogeneity for solid-liquid mixing process on the basis of four pitched-blade impeller and circle package impeller. The optimum aperture ratio and aperture diameter were $11.8 \%$ and $8 \mathrm{~mm}$, respectively, for solid particles suspension process in this work. Smaller particle diameter led to smaller settling velocity and higher solid particle suspension quality. More viscous liquid was easier for sustaining the solid particles in suspension state. Meanwhile, punched circle package impeller can reduce the power consumption compared with four pitched-blade impeller and circle package impeller at the same impeller speed, and enhance the solid integrated velocity, turbulent kinetic energy, and turbulent kinetic energy dissipation rate of solid-liquid mixing system at the same power consumption.
\end{abstract}

Keywords: CFD simulation; punched circle package impeller; solid-liquid suspension; stirred tank.

\footnotetext{
${ }^{*}$ Corresponding author: Deyin Gu, School of Environment and Resources, Chongqing Technology and Business University, Chongqing 400060, China, E-mail: gdy0811@ctbu.edu.cn

Mei Ye, School of Environment and Resources, Chongqing Technology and Business University, Chongqing 400060, China

Zuohua Liu, School of Chemistry and Chemical Engineering, Chongqing University, Chongqing 400044, China
}

\section{Introduction}

Examples of solid-liquid suspension in the stirred tank are commonly found in the mineral, crystallization, polymerization, precipitation, catalytic reactions, food processing and water treatment processes (Ibrahim et al. 2015; Montante et al. 2001; Pinelli, Montante, and Magelli 2004; Wang et al. 2017). Such processes usually require a highly effective contact between the solid and liquid phases, and ensure that the solid-liquid system is homogenous or solid particles are uniformly distributed throughout the stirred tank. Solid particles suspension rate is of importance to chemical reaction rate or mass transfer rate, which may significantly affect the product quality and yield (Klenov and Noskov 2011; Kumaresan and Joshi 2006; Micheletti et al. 2003).

Solid-liquid two-phase mixing characteristics in the stirred tank has been extensively studied in the literatures (Chen et al. 2011; Kasat et al. 2008; Khopkar et al. 2016). For the sake of improving solid particles suspension rate, the conventional operation is to enhance the pumping capacity of the impeller by increasing the agitation speed of the impeller. However, high energy consumption is required to reach an acceptable homogenous degree for the solid-liquid mixing system. In general terms, solidliquid suspension characteristics are largely determined by the types and structures of the impeller. Improvements in impeller design has been considered as a means to enhance the solid particles suspension quality or improve the solid-liquid mixing efficiency. There are many research reports that explore the impacts of impeller design and operation in improving the solid-liquid mixing performance in the stirred tank. Xu et al. (2013) applied a logarithmic helicoidal impeller in the solid-liquid suspension process, and found that logarithmic helicoidal impeller could improve the solid-liquid suspension quality compared with Rushton disc turbine impeller at the same power consumption. Liu et al. (2013) proposed a rigid-flexible combination impeller and applied it in the self-floating particles mixing process, and found that rigid-flexible combination impeller could improve the homogenous degree of self-floating particles in the liquid phase compared with rigid impeller under the constant 
power consumption. Liu et al. (2018) studied the solid particles suspension characteristics in the coaxial mixers, found that the coaxial mixers with the inner up-pumping impeller and six $45^{\circ}$ pitched-blade turbine impeller had obvious superiority compared with the combination of anchor and Rushton turbine in terms of power consumption. Zhao, Quan, and Liang (2007) applied a punched impeller in the phosphorite-water mixing process, and found that punched impeller could enhance the solid particles suspension degree compared with traditional impeller. $\mathrm{Gu}$ et al. (2017a) studied the hydrodynamics of solid-liquid suspension process in a stirred tank with punched rigid-flexible impellers, and found that punched rigid-flexible impeller could improve the solid particles suspension quality compared with the rigid impeller and rigid-flexible impeller at the same power consumption. According to the literature review, the suspension process of solid particles was that the solid particles gain energy from the vortexes in the flow field, and overcome their own gravity and the resistance of the fluid to rise up. Therefore, in order to further improve the suspension quality of solid particles, it is necessary to enhance the pumping capacity of the impeller, and intensify the local energy dissipation process of the flow field under the premise of ensuring sufficient main convection. Based on our previous studies ( $\mathrm{Gu}$ et al. 2017a, 2017b), a type of punched circle package impeller is proposed to improve the homogeneity of solid-liquid twophase system in this work.

As an effective and powerful method, computational fluid dynamics (CFD) simulation has been increasingly used to predict the hydrodynamic characteristics of solidliquid two-phase flows (Tamburini et al. 2011, 2012). Significant simulation results can be obtained and used for the reliable design and accurate control of solid-liquid mixing operating parameters. As for a solid-liquid stirred tank, the solid particle volume fraction distribution, solid-liquid turbulent characteristics, and solid particles velocity distribution etc., are fundamental concepts and parameters to investigate the fluid dynamics of solid-liquid two-phase. Tamburini et al. (2013) simulated the flow of dense solidliquid partial suspensions in baffled stirred tank at different agitation speeds with an Eulerian-Eulerian model coupled with a standard $k-\varepsilon$ turbulence model. Mishra and Ein-Mozaffari 2017 used CFD simulation to investigate the agitation speed, solid particle concentration, solid particle diameter, specific gravity of solid particle and the use of baffles on the mixing efficiency of the Maxblend impeller in term of the uniformity of the solid particles distribution. Liu et al. (2019) investigated the effects of agitation speed, the rotation mode of coaxial mixer, solid phase properties on the solid particle velocity distribution, solid particle volume fraction distribution and just-suspension speed based on the Eulerian-Eulerian model and modified Brucato drag model. Wadnerkar et al. (2012) employed CFD simulation to investigate the effects of impeller speed and initial solid loading on the just suspension speed, turbulent kinetic energy, and cloud height on the basis of an EulerianEulerian model and a standard $k-\varepsilon$ turbulence model. Hosseini et al. (2010) investigated the effects of impeller type, impeller off-bottom clearance, impeller speed, solid particle size, and solid particle specific gravity on the solidliquid suspension quality by using CFD simulation. Through the above literature review, it can be seen that CFD simulation is satisfactory tool to conduct the impeller configuration optimization and accurate control of solidliquid mixing operating parameters.

In this work, the major aim was to explore and analyze the mixing performance of punched circle package impeller for solid-liquid suspension process in a stirred tank employing the CFD simulation. The solid particle suspension characteristics in a stirred tank with four pitched-blade impellers, circle package impellers, and punched circle package impellers were comparatively investigated. Axial solid concentration profile, solid concentration distribution, cloud height, solid sediment height, just suspension speed, solid integrated velocity, turbulent kinetic energy, and turbulent kinetic energy dissipation rate in the stirred tank were predicted to evaluate the effectiveness and efficiency of the three different impellers (four pitched-blade impeller, circle package impeller, and punched circle package impeller). The effects of impeller speed, power consumption, impeller type, aperture size/ratio, solid particle diameter and liquid viscosity on the solid particle suspension quality were investigated.

\section{Physical system}

Schematic diagram of the solid-liquid stirred tank is shown in Figure 1. The solid particles suspension characteristics in a flat-bottom transparent cylindrical tank with inner diameter of $T=0.48 \mathrm{~m}$ was predicted by using CFD simulation. Four equally spaced vertical baffles with a width of $W=0.048 \mathrm{~m}(T / 10)$ were mounted symmetrically. The height $(H)$ of the liquid from tank bottom was maintained at $0.8 \mathrm{~m}$. The schematics of four pitched-blade impeller, circle package impeller, and punched circle package impeller are shown in Figure 2. Circle package impeller has a package circle piece with a width of $0.04 \mathrm{~m}$ and a thickness of $0.002 \mathrm{~m}$ around the blade tip of four pitched- 


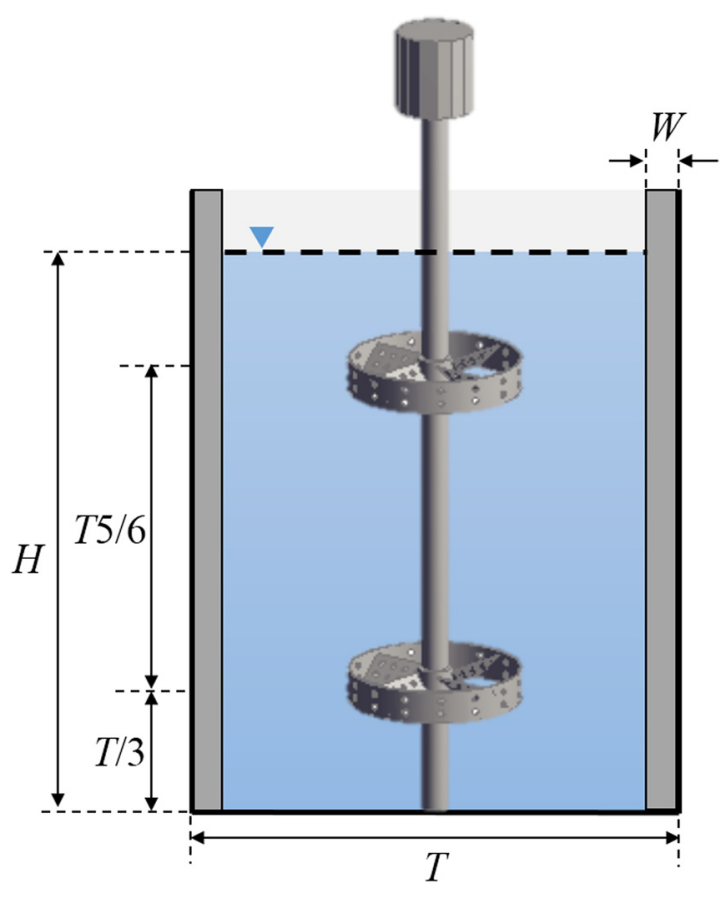

Figure 1: Schematic of the stirred tank.

blade impeller. Punched circle package impeller has some additional apertures on the surface of impeller blade and package circle piece on the basis of circle package impeller. The impeller off-bottom clearance was set at $T / 3$, and the impeller spacing between the upper and lower impellers was set at T5/6. A torque transducer (DaYang Company, Model: HX-90D) was used to measure the impeller power consumption. The dispersion of glass bead particles of density $\rho_{s}=2470 \mathrm{~kg} / \mathrm{m}^{3}$ in tap water $\left(\rho_{l}=1000 \mathrm{~kg} / \mathrm{m}^{3}\right.$, $\mu=0.001 \mathrm{~Pa} \mathrm{~s}$ ) at room temperature was investigated.

\section{Mathematical models}

\subsection{Model equations}

Hydrodynamic simulations were conducted using the Eulerian-Eulerian multiphase model. In this model, each phase is treated as an interpenetrating continuum represented by a volume fraction at each point of the system. Reynolds-averaged mass and momentum balance equations are solved for each phase. The governing equations are as follows:

Continuity equation (Ljungqvist and Rasmuson 2001; Wadnerkar et al. 2012, 2016):

$$
\frac{\partial\left(\alpha_{i} \rho_{i}\right)}{\partial t}+\nabla\left(\alpha_{i} \rho_{i} \vec{U}_{i}\right)=0
$$

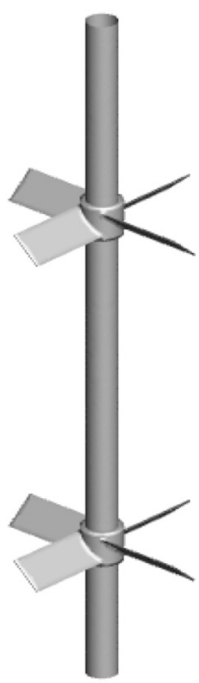

(a)

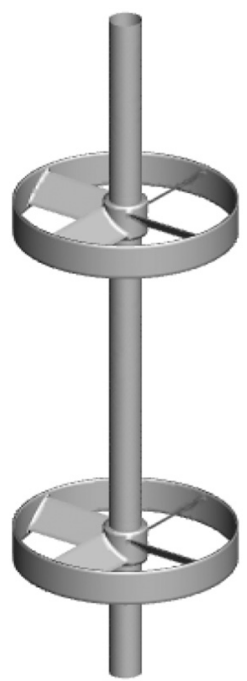

(b)

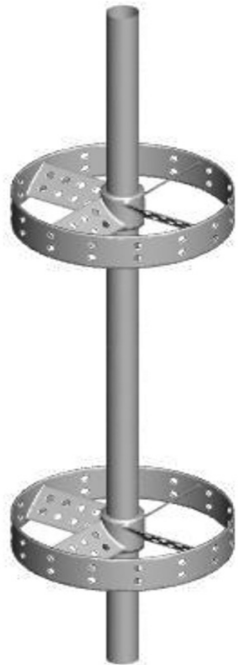

(c)
Figure 2: Structure diagram of the impellers.
(a) Four pitched-blade impeller,
(b) Circle package impeller,
(c) Punched circle package impeller.

Momentum equation (Ljungqvist and Rasmuson 2001; Wadnerkar et al. 2012, 2016):

$$
\begin{aligned}
\frac{\partial\left(\alpha_{i} \rho_{i} \vec{U}_{i}\right)}{\partial t}+\nabla\left(\alpha_{i} \rho_{i} \vec{U}_{i} \vec{U}_{i}\right)= & -\alpha_{i} \nabla p+\nabla \overline{\bar{\tau}}_{i}+\alpha_{i} \rho_{i} \vec{g}+\vec{R}_{i j} \\
& +\vec{F}_{i}
\end{aligned}
$$

where $i$ is $l$ or $s$ for the liquid phase or solid phase, respectively, $\rho$ is density, $\vec{U}$ is the velocity vector, $P$ is pressure and is shared by both the phases, $\overline{\bar{\tau}}$ is the stressstrain tensor because of viscosity and velocity fluctuations, $\vec{g}$ is gravity acceleration, $\vec{R}_{i j}$ is the interaction force between phase $i$ and phase $j$, and $\vec{F}_{i}$ is the effects of external force, turbulent dispersion force, virtual mass force and lift force, etc. $\alpha$ is the volume fraction, and it satisfies:

$$
\sum_{i=l, s} \alpha_{i}=1
$$

The stress-strain tensor is due to viscosity and Reynolds stresses that include the effect of turbulent fluctuations. Using the Boussinesq's eddy viscosity hypothesis the closure can be given to the above momentum transfer equation. The equation can be given as (Ljungqvist and Rasmuson 2001; Wadnerkar et al. 2012, 2016):

$$
\overline{\bar{\tau}}_{i}=\alpha_{i} \mu_{i}\left(\nabla \vec{U}_{i}+\nabla \vec{U}_{i}^{T}\right)+\alpha_{i}\left(\lambda_{i}-\frac{2}{3} \mu_{i}\right) \nabla \vec{U}_{i} \overline{\bar{I}}
$$


where $\mu$ is the shear viscosity, $\lambda$ is bulk viscosity and $\bar{I}$ is the unit stress tensor.

\subsection{Turbulence equations}

In order to enclose the momentum equation, the general solution is to get Reynolds stress by computing turbulent kinetic energy $(k)$ and turbulent dissipation rate $(\varepsilon)$. The standard $k-\varepsilon$ mixture turbulence model was adopted to simulate flows in the stirred tank, and governing equations are written as (Ljungqvist and Rasmuson 2001; Wadnerkar et al. 2016):

$$
\begin{aligned}
\frac{\partial}{\partial t}\left(\rho_{m} k\right)+\nabla\left(\rho_{m} \vec{U}_{m} k\right)=\nabla & {\left[\left(\mu_{m}+\frac{\mu_{t, m}}{\sigma_{k}}\right) \nabla k\right]+G_{k, m}-\rho_{m} \varepsilon } \\
\frac{\partial}{\partial t}\left(\rho_{m} \varepsilon\right)+\nabla\left(\rho_{m} \vec{U}_{m} \varepsilon\right)=\nabla & {\left[\left(\mu_{m}+\frac{\mu_{t, m}}{\sigma_{\varepsilon}}\right) \nabla \varepsilon\right]+\frac{\varepsilon}{k}\left(C_{1 \varepsilon} G_{k, m}\right.} \\
& \left.-C_{2 \varepsilon} \rho_{m} \varepsilon\right)
\end{aligned}
$$

where $\rho_{m}, \mu_{m}$, and $\mu_{t, m}$ are the density, molecular viscosity and turbulent viscosity for the mixture respectively, and they can be calculated by:

$$
\begin{gathered}
\rho_{m}=\sum_{i=l, s} \alpha_{i} \rho_{i} \\
\mu_{m}=\sum_{i=l, s} \alpha_{i} \mu_{i} \\
\vec{U}_{m}=\frac{\sum_{i=l, s} \alpha_{i} \rho_{i} \vec{U}_{i}}{\sum_{i=l, s} \alpha_{i} \rho_{i}} \\
\mu_{t, m}=\rho_{m} C_{\mu} \frac{k^{2}}{\varepsilon} \\
G_{k, m}=\mu_{t, m}\left[\nabla \vec{U}_{m}+\left(\nabla \vec{U}_{m}\right)^{T}\right]: \nabla \vec{U}_{m}
\end{gathered}
$$

where the $C_{\varepsilon 1}, C_{\varepsilon 2}, C_{\mu}, \sigma_{k}$, and $\sigma_{\varepsilon}$ are the parameters in the standard $k-\varepsilon$ model, and the values of the parameters are selected as follows (Kasat et al. 2008; Wadnerkar et al. 2012): $C_{\varepsilon 1}=1.45, C_{\varepsilon 2}=1.9, C_{\mu}=0.09, \sigma_{k}=1.0$, and $\sigma_{\varepsilon}=1.3$.

\subsection{Interphase drag force}

The interphase drag is the resultant force experienced by a particle in the direction of relative motion due to a moving fluid. In solid-liquid system, many interphase forces (i.e., drag force, lift force, Basset force, virtual mass force) may play a significant role in multiphase flow field simulation. According to the literature review, drag force was the most dominant when the $\rho_{\mathrm{s}} / \rho_{l}>2$, and other forces can be neglected (Ljungqvist and Rasmuson 2001; Nurtono et al. 2009). Therefore, only the drag force was considered in this work.

$$
F_{\mathrm{drag}}=\frac{3}{4} \frac{C_{D}}{d_{p}} \alpha_{s} \rho_{l}\left|\vec{U}_{s}-\vec{U}_{l}\right|\left(\vec{U}_{s}-\vec{U}_{l}\right)
$$

where the $C_{D}$ is the drag coefficient and $d_{p}$ is the particle diameter. Considering the solid concentration is low in this wok, the $C_{D}$ can be obtained from the Wen-Yu correction (Ljungqvist and Rasmuson 2001; Wen and Yu 1996):

$$
\begin{gathered}
C_{D}=\frac{24}{\alpha_{l} \operatorname{Re}}\left[1+0.15\left(\alpha_{l} \operatorname{Re}\right)^{0.687}\right] \\
\operatorname{Re}=\frac{\rho_{l} d_{p}}{\mu_{l}}\left|\vec{U}_{s}-\vec{U}_{l}\right|
\end{gathered}
$$

\subsection{Numerical details}

The multiple reference frame (MRF) method was selected to simulate the rotation of impellers. The solution domain was divided into two parts, as shown in Figures 3 and 4. The inner rotating zone was created with the dimensions $r=0.12 \mathrm{~m}$ and $0.13 \mathrm{~m}<z<0.59 \mathrm{~m}$ (where $z$ is the axial distance from the bottom of stirred tank), and the outer part was the non-rotating domain. The inner rotating zone was discretized by tetrahedral cells (unstructured grid) because of the complex geometry, and the outer domain was discretized by hexahedron cells (structure grid) (Hosseini et al. 2010). The optimum grid size was obtained by decreasing the size to a final value below which the

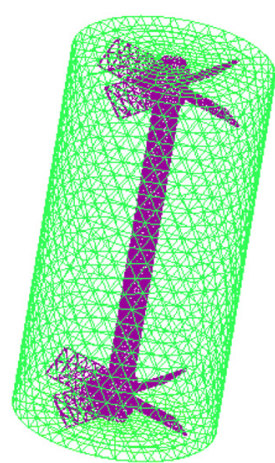

(a)

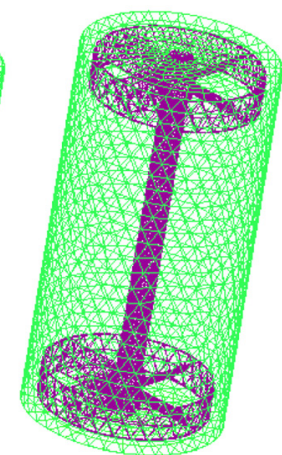

(b)

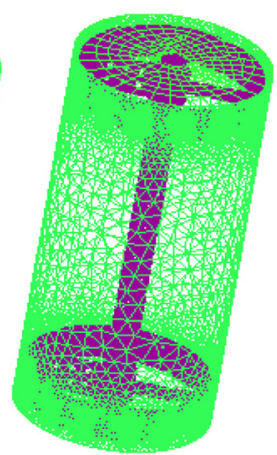

(c)
Figure 3: The inner rotating domain.

(a) Four pitched-blade impeller,

(b) Circle package impeller,

(c) Punched circle package impeller. 


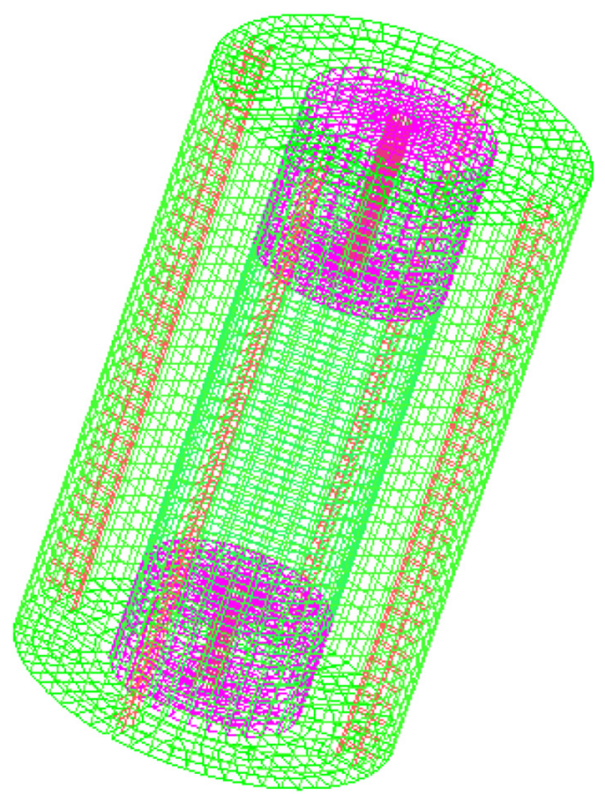

Figure 4: The outer non-rotating domain.

changes in the velocity and solid concentration profiles were less than $3 \%$. The number of cells used for four pitched-blade impeller stirred tank, circle package impeller stirred tank, and punched circle package impeller stirred tank were 16,37,394, 16,03,118, and 25,00,815, respectively. The SIMPLEC algorithm was used to solve pressure-velocity coupling, and the standard wall function with no slip shear condition was selected. In order to mitigate the effects of false diffusion and improve accuracy of simulation results, the high order upwind scheme was adopted. The relative residual was set at $10^{-5}$, which is considered as the index of convergence. The time step used in the simulation was $0.005 \mathrm{~s}$, and total simulation time was $50 \mathrm{~s}$. The transient state numerical solution of the system was obtained using the commercial analytical software ANSYS FLUENT 14.5 (ANSYS company, USA).

\section{Results and discussions}

\subsection{Comparison of simulated results and experimental data}

It is imperative to mention that the validation of the generated CFD model was done by comparing the results obtained from the simulation to experimental data in terms of local axial solid concentration profiles. In order to validate the CFD model, the solid concentration at seven axial positions of the stirred tank where $z / H=0.125,0.25,0.375$, $0.5,0.625,0.75$, and 0.875 at $r / R=0.8$ was measured with

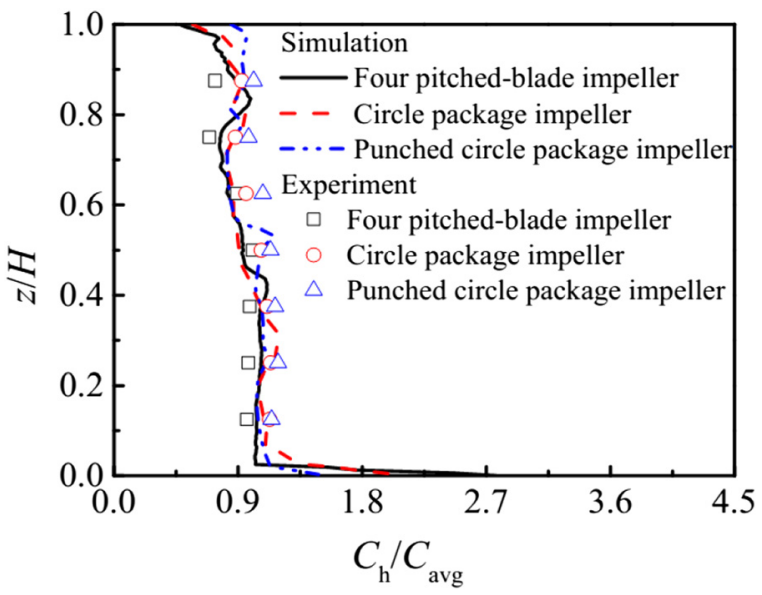

Figure 5: Comparison of local axial solid concentration profiles between simulation and experiment $\left(N=5 \mathrm{~s}^{-1}\right.$, particle diameter $\left.=120 \mu \mathrm{m}, \mu=1 \times 10^{-3} \mathrm{~Pa} . \mathrm{s}, r / R=0.8\right)$.

the sampling method (Dohi et al. 2004; Takahashi and Sasaki 1999). As shown in Figure 5, the variation trend of local axial solid concentration between simulation and experiment were consistent, and the standard deviation value between simulation and experiment was noticed to be less than $5 \%$.

\subsection{Effects of impeller speed and impeller type}

Figure 6 illustrates the local axial solid concentration profiles at $r / R=0.8$ as a function of impeller speed for the three different impellers (four pitched-blade impeller, circle package impeller, punched circle package impeller) at different impeller speeds, Figure 7 shows the simulated contour plots of solid concentration on horizontal planes at different vessel heights (i.e. $z=0,0.3,0.5,0.7,0.9 \mathrm{H}$ ) for different impeller speeds, and Figure 8 shows the cloud height representation via iso-surface of the average volume fraction $\left(C_{\text {avg }}=0.1\right)$ at the same operating conditions. As can be seen in Figures 6 and 7, at the low impeller speed, the solid particles in the stirred tank had a large concentration gradient in the axial direction of stirred tank, and a large number of solid particles were still deposited at the bottom of stirred tank and not suspended. The concentration of solid particles in the upper part of stirred tank was low and the solid particles suspension quality was poor. It can be seen in Figure 8, the cloud height was very low at the low impeller speed. As the impeller speed increased, the solid particles at the bottom of stirred tank were suspended to the upper part of stirred tank, the solid concentration gradient in the axial direction of stirred tank decrease 

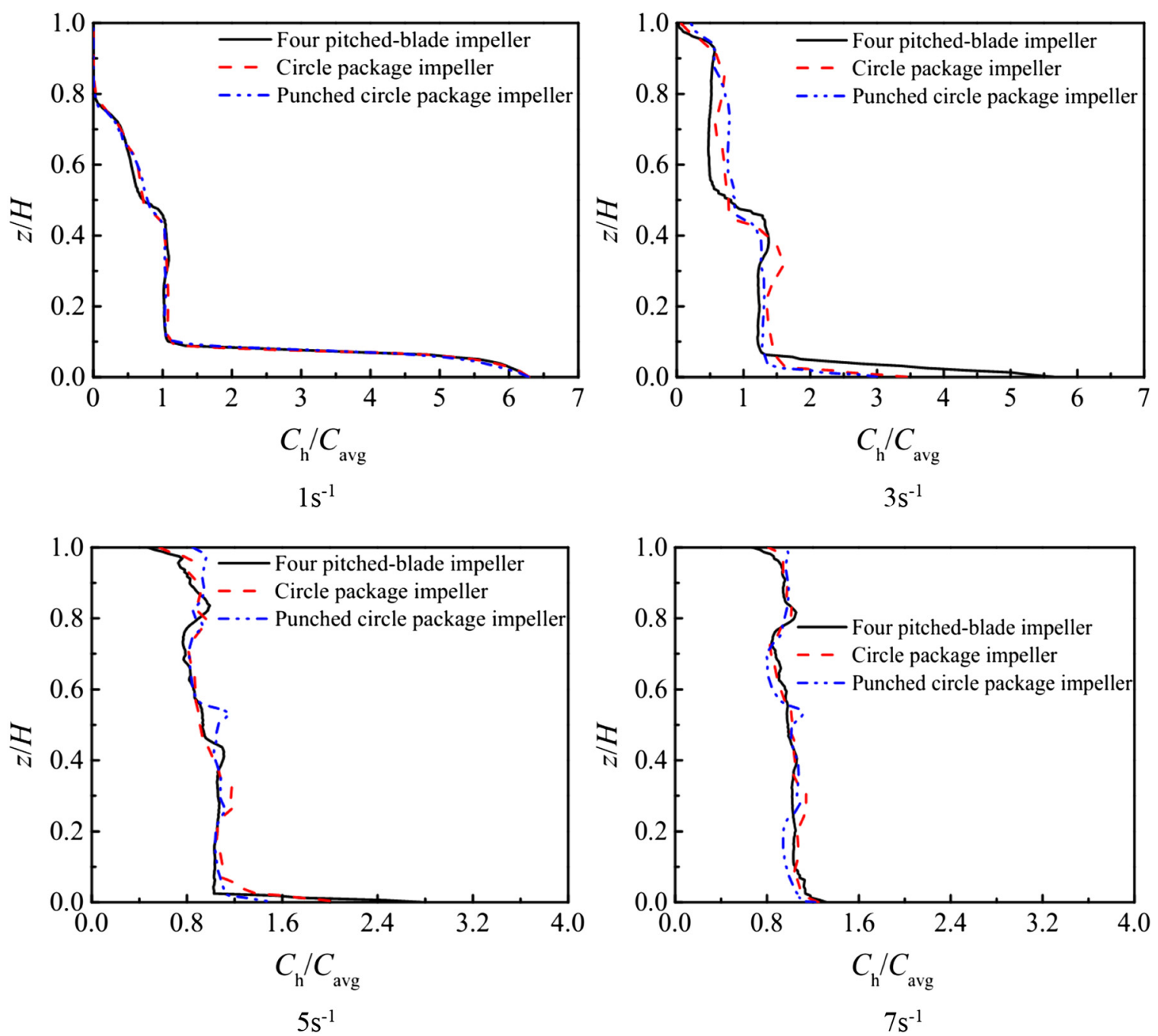

Figure 6: Effect of impeller speed on local axial solid concentration profile (particle diameter $=120 \mu \mathrm{m}, \mu=1 \times 10^{-3} \mathrm{~Pa} \mathrm{~S}, r / R=0.8$ ).

gradually, and the cloud height increase gradually. It can be also observed that circle package impeller could increase the homogenous degree of solid-liquid system compared with four pitched-blade impeller, and punched circle package impeller could further improve the solid particle suspension quality on the basis of circle package impeller. These phenomena might be explained by the fact that circle package impeller has a package circle piece around the blade tip of four pitched-blade impeller, which can increase the pumping capacity of the impeller, and more solid particles can be easily suspended to the upper part of stirred tank. Punched circle package impeller could produce a series of jet flows due to the existence of aperture, and the jet flows could improve the turbulence extent of the mixing system (Liu et al. 1999; Yang, Wang, and Wang 2015), which was beneficial to the suspension process of solid particles.

\subsection{Effects of aperture ratio and aperture diameter}

Figure 9 shows the effects of aperture ratio and aperture diameter of punched circle package impeller on the local axial solid concentration profile at $r / R=0.8$. Punched circle package impeller can produce a series of jet flows in the rotation process, the shear action of the jet flows on the surrounding fluid will increase the velocity gradient, and many vortices will be formed. In this way, the local energy dispersion process can be intensified and the turbulent degree of solid-liquid mixing system can be increased, which was beneficial to the suspension process of solid particles. As can be seen in Figure 9, aperture ratio and aperture diameter of punched circle package impeller had a significant effect on the local axial solid concentration profile. As observed in Figure 9a, if aperture ratio was too 


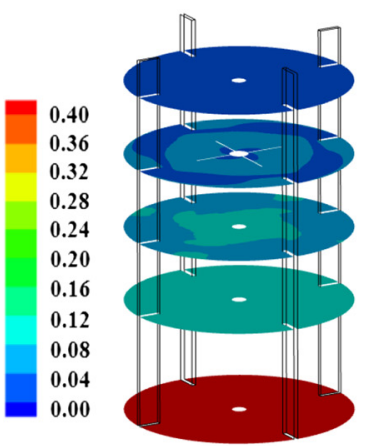

$1 \mathrm{~s}^{-1}$

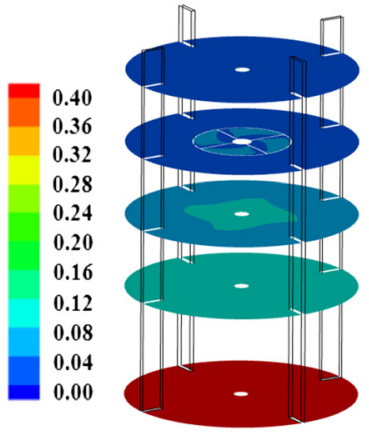

$1 \mathrm{~s}^{-1}$

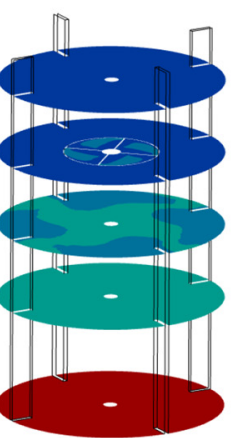

$1 \mathrm{~s}^{-1}$

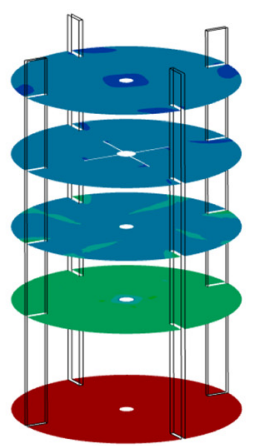

$3 \mathrm{~s}^{-1}$

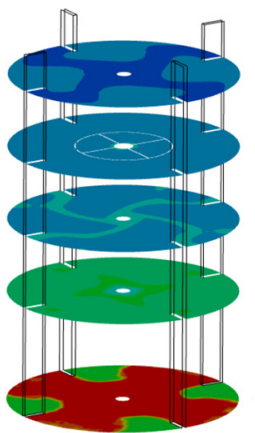

$3 \mathrm{~s}^{-1}$

(b)

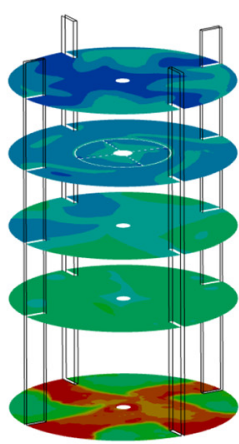

$3 \mathrm{~s}^{-1}$

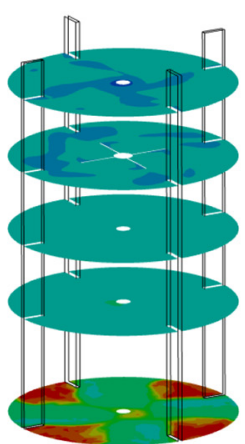

$5 \mathrm{~s}^{-1}$

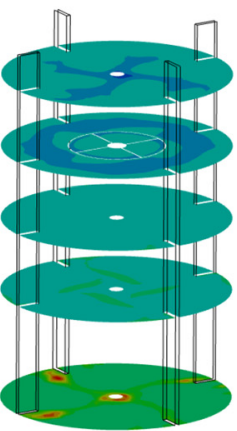

$5 \mathrm{~s}^{-1}$

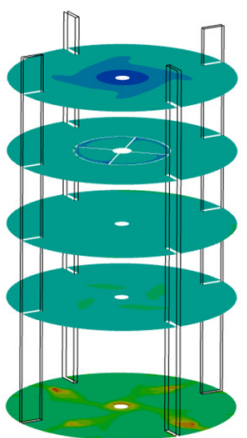

$5 \mathrm{~s}^{-1}$

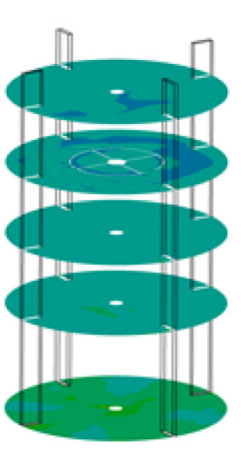

$7 \mathrm{~s}^{-1}$

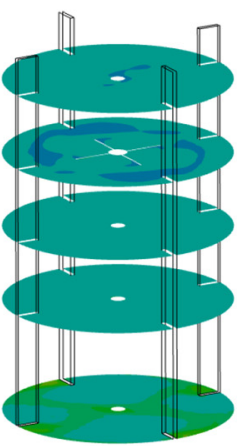

$7 \mathrm{~s}^{-1}$

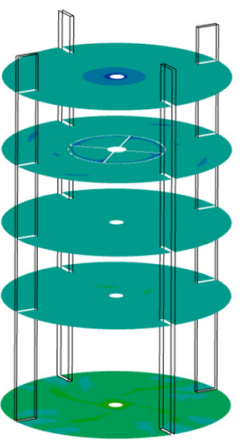

$7 \mathrm{~s}^{-1}$
Figure 7: Contour plots of solid volumetric fraction on horizontal planes at different vessel heights (i.e. $z=0,0.3,0.5,0.7,0.9 H$ ) and different impeller speeds (particle diameter $=120 \mu \mathrm{m}, \mu=1 \times 10^{-3} \mathrm{~Pa} \mathrm{~s}$ ). (a) Four pitched-blade impeller, (b) Circle package impeller, (c) Punched circle package impeller.

(c)

high, the main convection diffusion will be weakened. Even if the eddy diffusion was very strong, it was only limited to the vicinity of the impeller blade, and it was impossible to completely suspend the solid particles to the whole stirred tank. Moreover, if aperture was too low, not enough vortices will be formed to reach the purpose for the intensification of eddy diffusion process. Therefore, aperture ratio of $11.8 \%$ was particularly suitable for the solid particles suspension process in this work. As shown in Figure $9 \mathrm{~b}$, if aperture diameter was too large, the orifice flow velocity was too small to form sufficient velocity gradient, so there was not enough strong shear stress, and the local eddy diffusion process cannot be intensified. If aperture diameter was too small, the energy consumed by the friction between the fluid and the edge of the aperture increased, and the utilization rate of impeller energy decreased. In addition, the parallel flows will be produced with the decrease of aperture diameter, and the part of kinetic energy between the parallel flows will be lost in the exchange process, thus causing a negative effect on the 


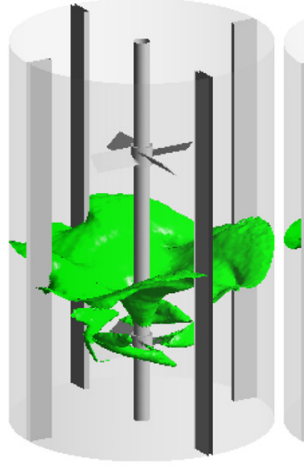

$1 \mathrm{~s}^{-1}$

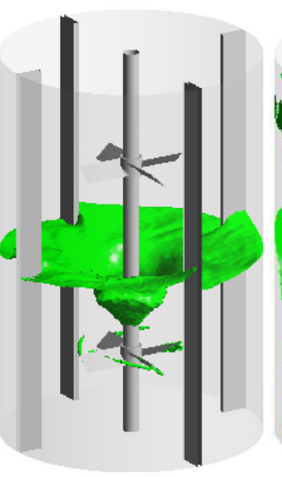

$3 \mathrm{~s}^{-1}$

(a)

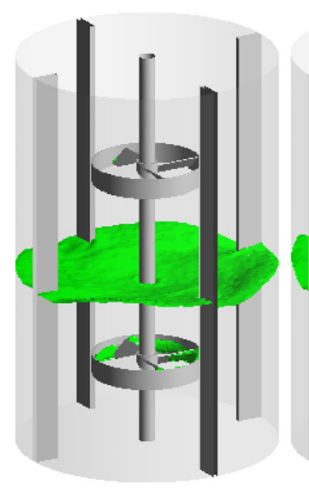

$1 \mathrm{~s}^{-1}$

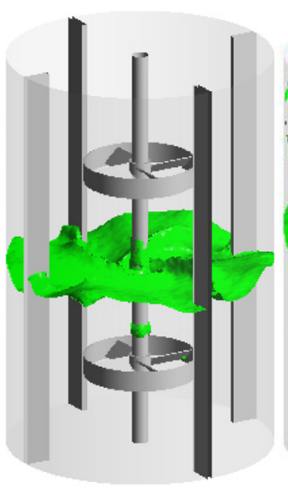

$3 \mathrm{~s}^{-1}$

(b)

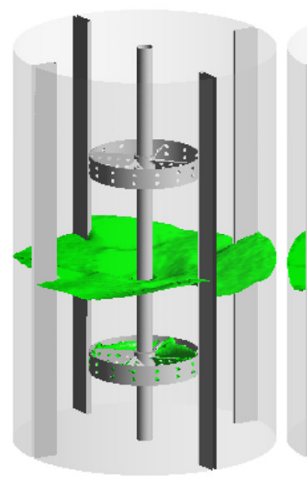

$1 \mathrm{~s}^{-1}$

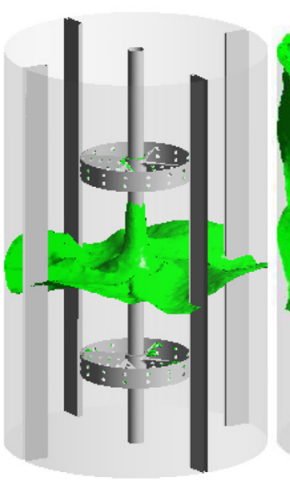

$3 \mathrm{~s}^{-1}$

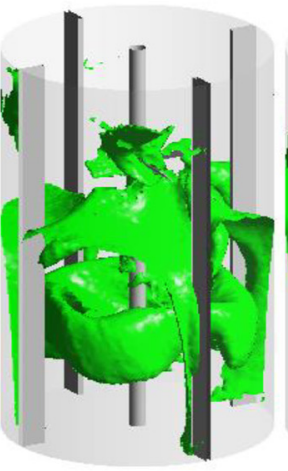

$5 \mathrm{~s}^{-1}$

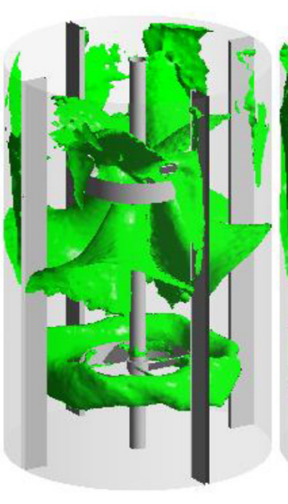

$5 s^{-1}$

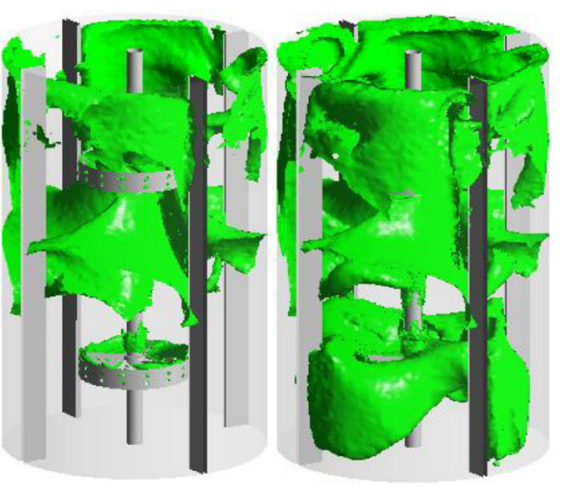

$5 s^{-1}$

(c)

eddy diffusion process. Therefore, aperture diameter of $8 \mathrm{~mm}$ was particularly suitable for the solid particles suspension process in this work.

\subsection{Effects of solid particle diameter}

Physical characteristics of the solid particles particularly the solid particle diameter significantly impact the mixing

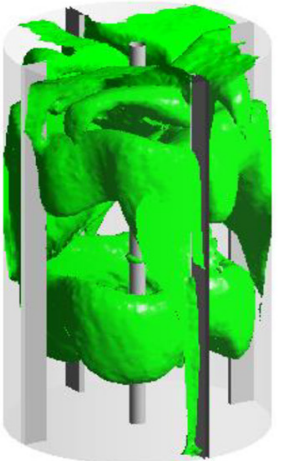

$7 \mathrm{~s}^{-1}$

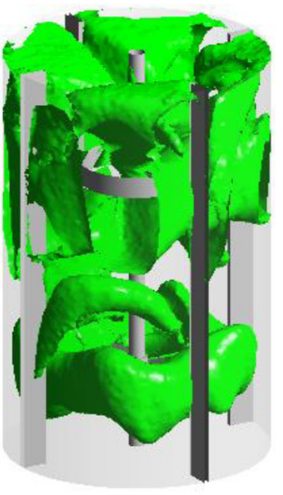

$7 \mathrm{~S}^{-1}$

Figure 8: Cloud height representation via iso-surface with $C_{a v g}=0.1$ at different impeller speeds (particle diameter $\left.=120 \mu \mathrm{m}, \mu=1 \times 10^{-3} \mathrm{~Pa} \mathrm{~s}\right)$.

(a) Four pitched-blade impeller,

(b) Circle package impeller,

(c) Punched circle package impeller. quality of the solid particle suspension. As can be observed in Figure 10, the homogenous degree of solidliquid system increased with a decrease in the solid particle diameter. It can be seen that the solid particle diameter of $50 \mu \mathrm{m}$ was distributed uniformly inside the stirred stank, while the solid particle diameter of 120 and $190 \mu \mathrm{m}$ still existed concentration gradient in the local axial solid concentration profile. The following equation (Hosseini et al. 2010; Liu et al. 2019) could shed light on 


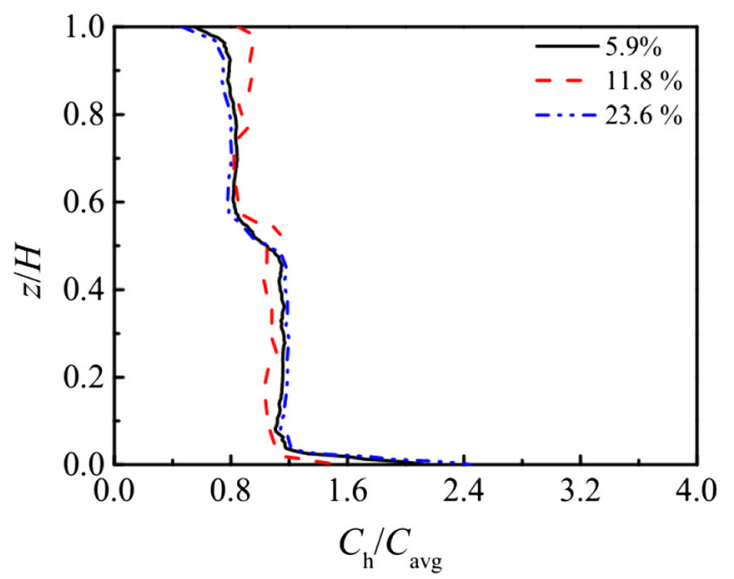

(a)

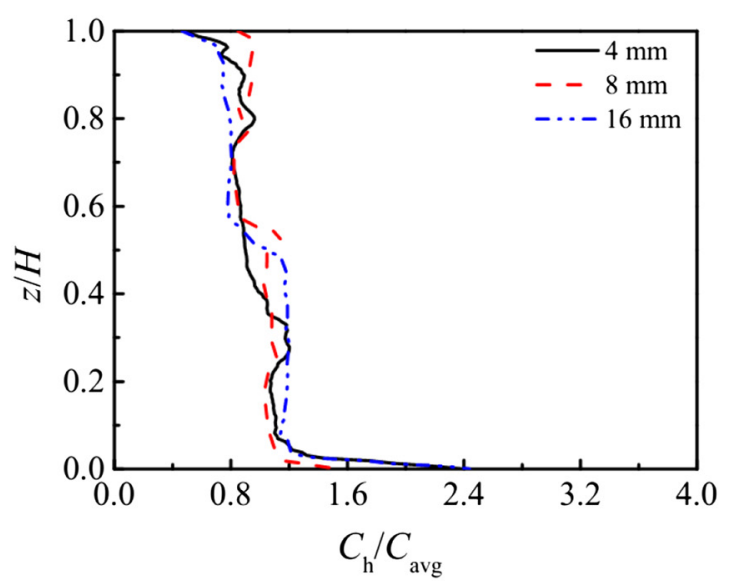

(b)

Figure 9: Effects of aperture ratio and aperture size of punched circle package impeller on local axial solid concentration profile ( $N=5 \mathrm{~s}^{-1}$, particle diameter $\left.=120 \mu \mathrm{m}, \mu=1 \times 10^{-3} \mathrm{~Pa} \mathrm{~s}, r / R=0.8\right)$.

(a) Effect of aperture ratio (aperture diameter $=8 \mathrm{~mm}$ ),

(b) Effect of aperture size (aperture ratio $=11.8 \%$ ).

the effect of solid particle diameter on solid-liquid suspension process.

$$
V_{t}=\left[\frac{4}{3} \frac{g d_{p}\left(\rho_{s}-\rho_{l}\right)}{C_{D} \rho_{l}}\right]^{\frac{1}{2}}
$$

where $V_{t}, C_{D}, \rho_{s}, \rho_{l}, d_{p}$, and $g$ are solid particle terminal settling velocity, the drag coefficient, density of solid particle, liquid density, diameter of particle and gravitational constant, respectively. The particle terminal settling velocity decreased with a decrement in solid particle diameter. Hence, settling of the smaller solid particles would be slower in comparison to that for the larger ones indicating that the uniform

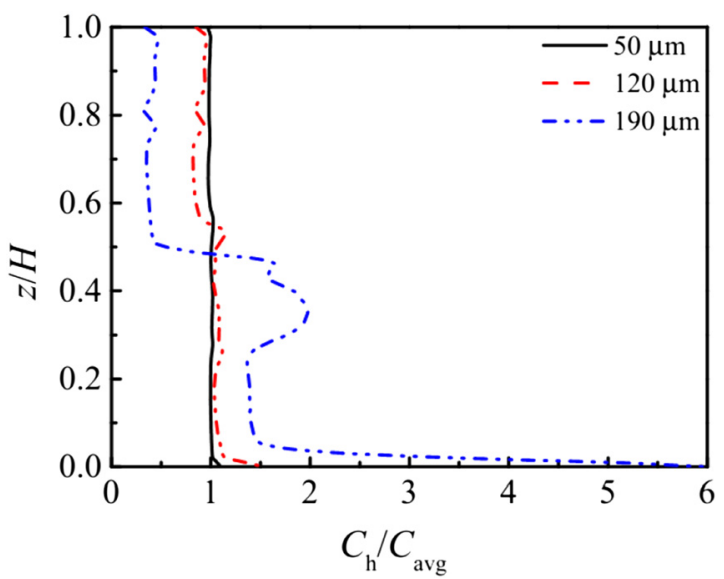

Figure 10: Effect of particle diameter on local axial solid concentration profile (punched circle package impeller, $N=5 \mathrm{~s}^{-1}$, $\left.\mu=1 \times 10^{-3} \mathrm{~Pa} \mathrm{~S}, r / R=0.8\right)$.

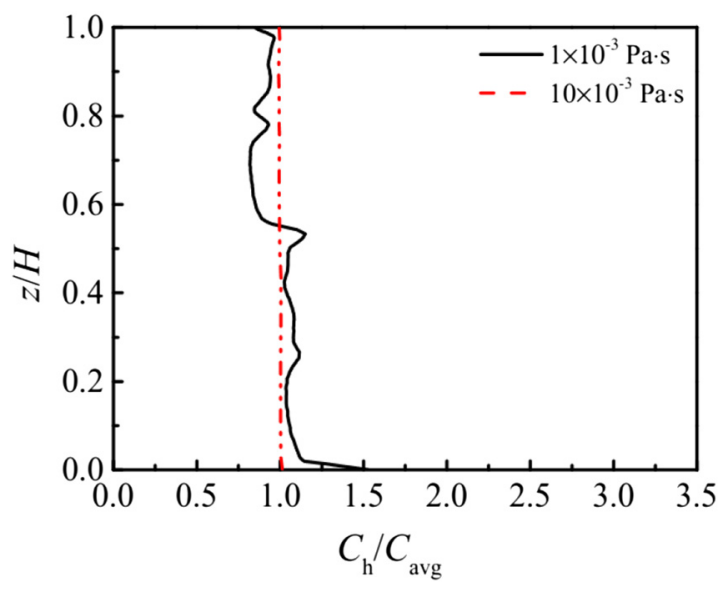

Figure 11: Effect of liquid viscosity on local axial solid concentration profile (punched circle package impeller, $N=5 \mathrm{~s}^{-1}$, particle diameter $=120 \mu \mathrm{m}, r / R=0.8)$.

distribution of the large solid particles would not be easier.

\subsection{Effects of liquid viscosity}

Figure 11 illustrates the effect of liquid viscosity on the local axial solid concentration profile. As shown in Figure 11, the local axial solid concentration profile at $r / R=0.8$ showed that a quite uniform distribution was found in a more viscous liquid. The more uniform solid particles distribution in a more viscous liquid can be explained by the fact that the higher viscous drag and the higher flow resistance 


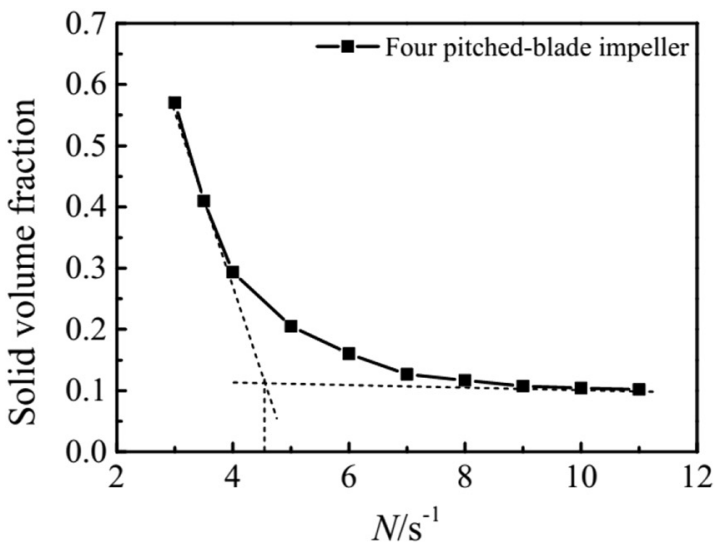

(a)

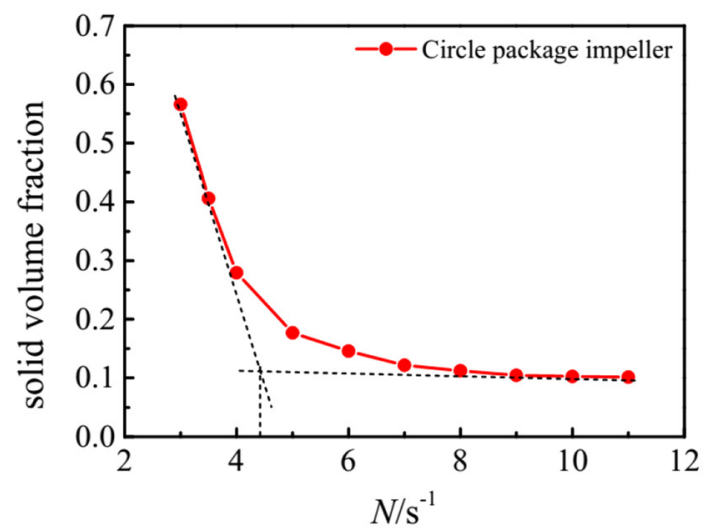

(b)

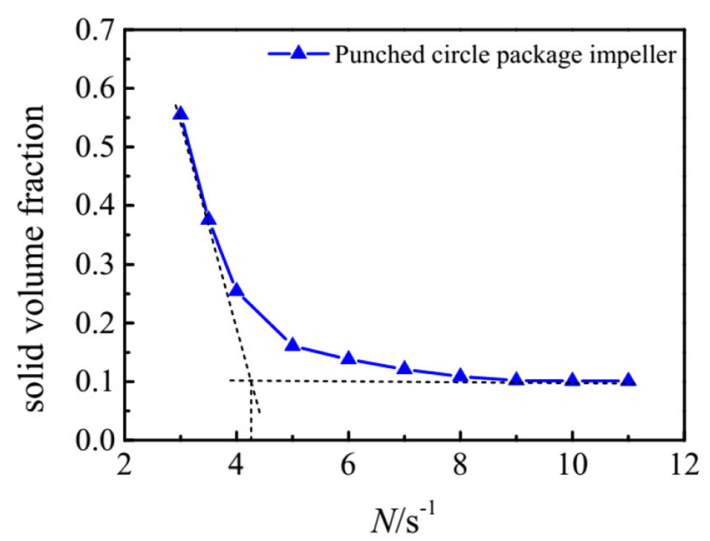

(c)

Figure 12: Estimation of just suspension speed using averaged solid volume fraction versus impeller speed for the three different impeller (particle diameter $=120 \mu \mathrm{m}, \mu=1 \times 10^{-3} \mathrm{~Pa} \mathrm{~s}$ ).

(a) Four pitched-blade impeller system,

(b) Circle package impeller,

(c) Punched circle package impeller.

in a more viscous liquid resulted in smaller settling velocity of solid particles, thus preventing solid particles from returning to the bottom of stirred tank after suspension in

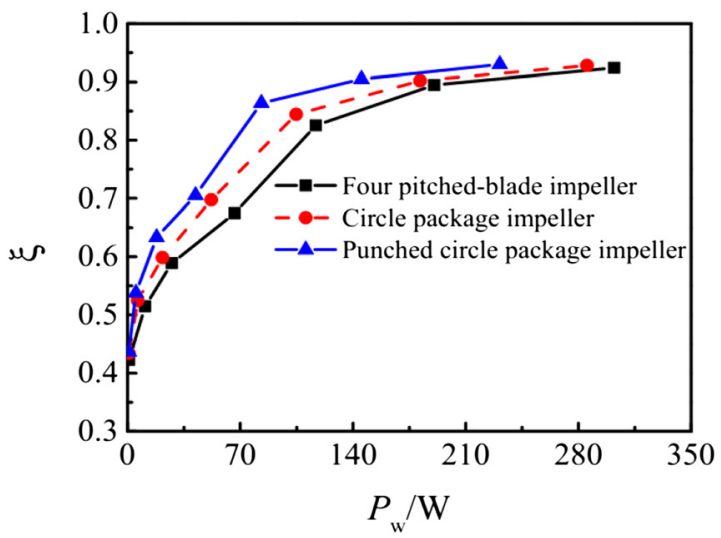

Figure 13: Comparison of $\xi$ at different power consumptions.

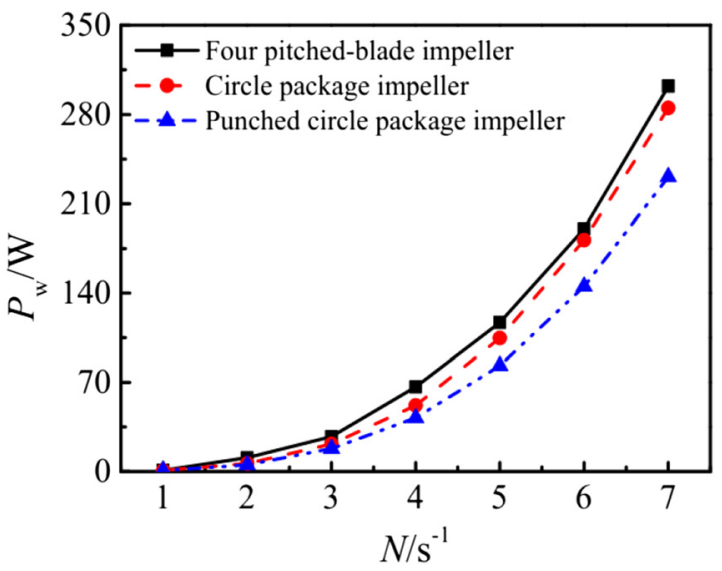

Figure 14: Comparison of $P_{w}$ at different impeller speeds.

the liquid phase, and less energy was required to maintain solid particles in suspension.

\subsection{Prediction of just suspension speed}

The just suspension speed $\left(N_{j s}\right)$ was adopted to examine the solid-liquid mixing quality in the stirred tank. The just suspension speed $\left(N_{j s}\right)$ was defined as the impeller agitation speed required to attain the solid particles complete (off-bottom) suspension in the solid-liquid stirred tank. The average solid volume fraction for a horizontal plane located $1 \mathrm{~mm}$ above the bottom of the stirred tank was measured at different impeller speeds by employing CFD model to determine $N_{j s}$. Two tangents (one at the point of minimum slope and another at the point of maximum slope) were drawn to the curve as shown in Figure 12. The just suspension speed $\left(N_{j s}\right)$ was the impeller agitation speed corresponding to the intersection point of the two tangents. The similar approach was used by Tamburini 


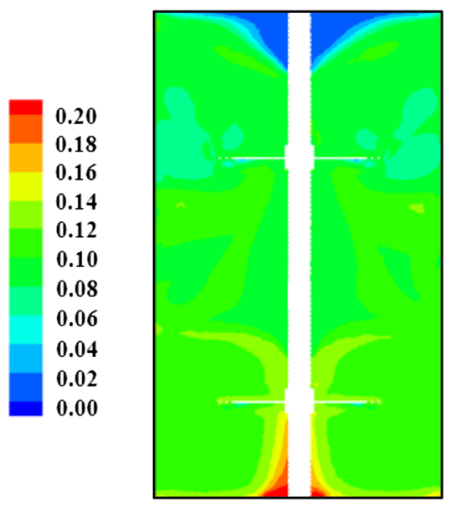

(a)

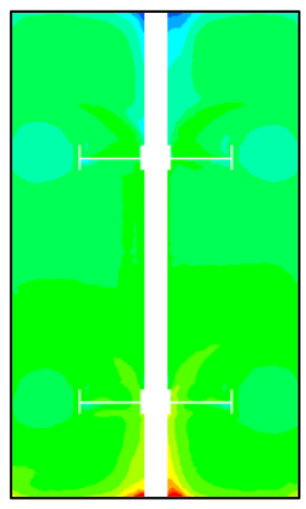

(b)

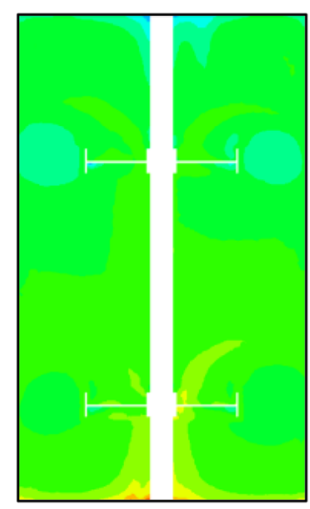

(c)
Figure 15: Contour plots of solid concentration for different impeller types at $P_{w}=100 \mathrm{~W}$ on $Y Z$ plane (particle diameter $\left.=120 \mu \mathrm{m}, \mu=1 \times 10^{-3} \mathrm{~Pa} \mathrm{~s}\right)$.

(a) Four pitched-blade impeller,

(b) Circle package impeller,

(c) Punched circle package impeller.

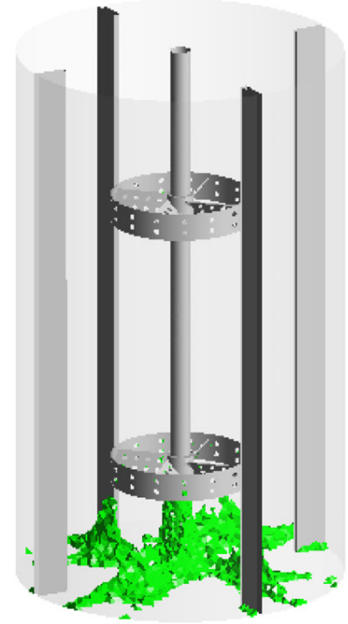

(c)

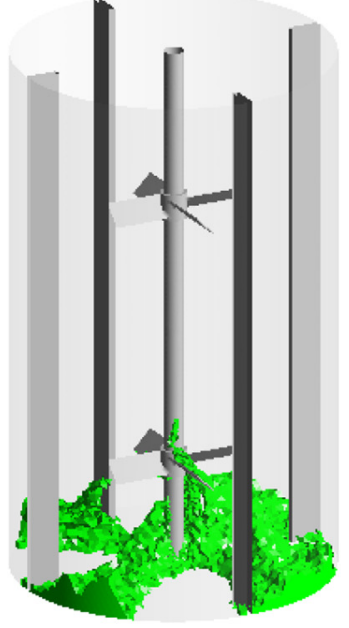

(a)

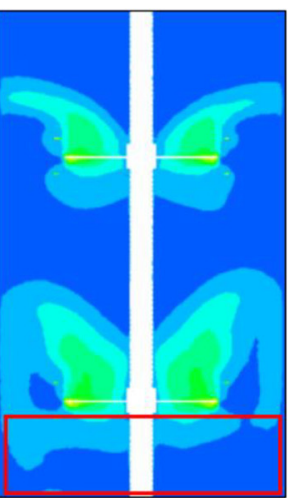

(a)

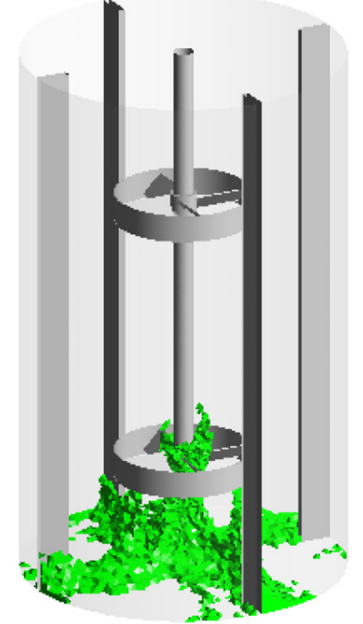

(b)

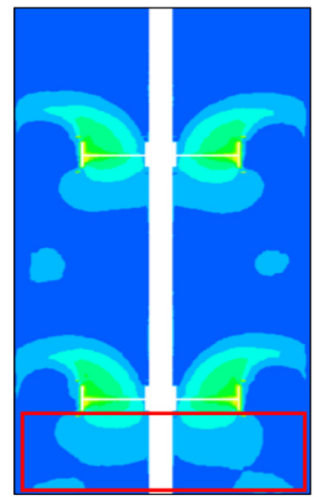

(b)

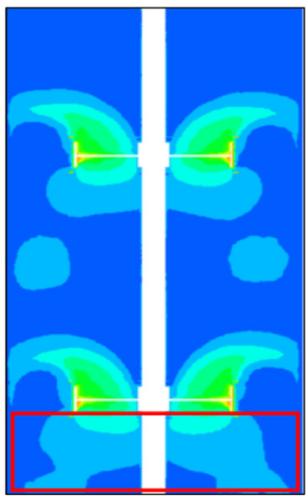

(c) fraction above $1.3 C_{\text {avg }}$ (dark region) for different impeller types at $P_{w}=100 \mathrm{~W}$ (particle diameter $=120 \mu \mathrm{m}$, $\mu=1 \times 10^{-3}$ Pa s).

(a) Four pitched-blade impeller,

(b) Circle package impeller,

(c) Punched circle package impeller.
Figure 16: The isovolume of solid volume

Figure 17: Contour plots of solid particle integrated velocity for different impeller types at $P_{w}=100 \mathrm{~W}$ on $Y Z$ plane (particle diameter $=120 \mu \mathrm{m}, \mu=1 \times 10^{-3} \mathrm{~Pa} \mathrm{~s}$ ).

(a) Four pitched-blade impeller,

(b) Circle package impeller,

(c) Punched circle package impeller. et al. (2013) and Hosseini et al. (2010) to estimate $N_{j s}$. As shown in Figure 12, the just suspension speed $\left(N_{j s}\right)$ was found to be $4.56 \mathrm{~s}^{-1}, 4.41 \mathrm{~s}^{-1}$, and $4.26 \mathrm{~s}^{-1}$ using this method for the four pitched-blade impeller, circle package impeller, and punched circle package impeller, respectively. It can be also found that circle package impeller could reduce the just suspension speed compared with four pitched-blade impeller, and punched circle package impeller could further reduce the just suspension speed on the basis of circle package impeller. It indicated 


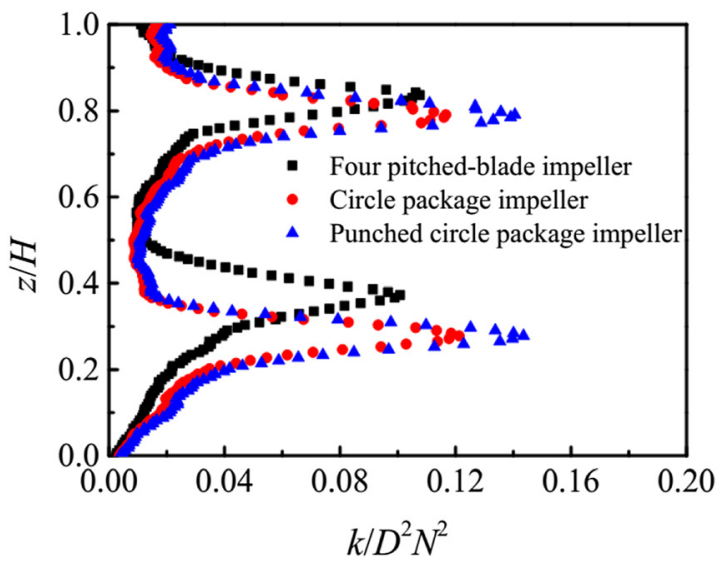

Figure 18: Turbulent kinetic energy for different impeller types at $P_{w}=100 \mathrm{~W}$ (particle diameter $=120 \mu \mathrm{m}, \mu=1 \times 10^{-3} \mathrm{~Pa} \mathrm{~s}, r / R=0.8$ ).

that punched circle package impeller was more efficient in suspending solid particles compared with four pitchedblade impeller and circle package impeller.

\subsection{Evaluation of solid particle suspension quality}

The homogeneity $\xi$ is widely used to evaluate the solid particles suspension quality in the literatures. In order to measure the solid particles suspension quality, the solid volume fractions at seven axial positions of the stirred tank where $z / H=0.125,0.25,0.375,0.5,0.625,0.75$, and 0.875 at $r / R=0.8$ were measured with sampling method. The homogeneity $\xi$ can be calculated by using the following equation (Hosseini et al. 2010; Tervasmaki, Tiihonen, and Ojamo 2014):

$$
\xi=1-\sqrt{\frac{\sum_{1}^{n}\left(C_{h}-C_{\text {avg }}\right)^{2}}{n}}
$$

where $n$ is the number of sampling points, $C_{h}$ is the local axial solid concentration, $C_{a v g}$ is the average solid concentration.

Figure 13 demonstrates the homogeneity $\xi$ as a function of power consumption $\left(P_{w}\right)$ for the three different impellers (four pitched-blade impeller, circle package impeller, punched circle package impeller). As shown in Figure 13, the higher $P_{w}$, the higher the solid particle suspension quality. It can be also observed that circle package impeller could improve the solid particles suspension quality compared with four pitched-blade impeller at the same power consumption, and punched circle package impeller was more efficient in term of solid particles suspension quality in liquid phase on the basis of circle package impeller.

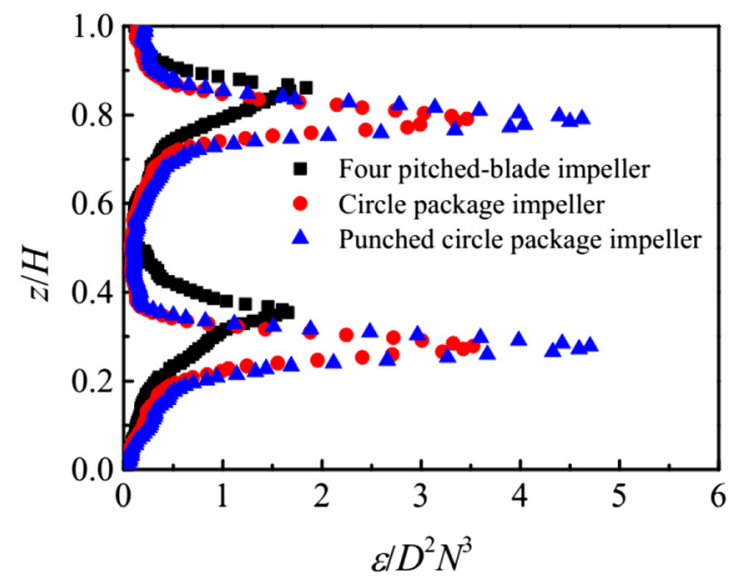

Figure 19: Turbulent kinetic energy dissipation rate for different impeller types at $P_{w}=100 \mathrm{~W}$ (particle diameter $=120 \mu \mathrm{m}$, $\left.\mu=1 \times 10^{-3} \mathrm{~Pa} \mathrm{~s}, r / R=0.8\right)$.

As shown in Figure 14, the power consumption $\left(P_{w}\right)$ of the three different impellers were compared with each other at the same impeller speed. It was observed that the power consumption of four pitched-blade impeller was highest among the three different impellers, and punched circle package impeller could reduce the power consumption on the basis of circle package impeller at the same impeller speed. It indicated that punched circle package impeller was the most efficient in the solid particle suspension process among the three different impellers.

\subsection{Solid suspension quality analysis}

It is necessary to compare the solid particles suspension status in the three different impeller systems (four pitchedblade impeller system, circle package impeller system, punched circle package impeller system) at the constant power consumption. Figure 15 demonstrates the contour plots of solid concentration for different impeller types at $P_{w}=100 \mathrm{~W}$ on $Y Z$ plane, and Figure 16 illustrates the threedimensional view of solid volume fraction isovolume above 1.3 $C_{\text {avg }}$ at the same power consumption. As illustrated in Figures 15 and 16, a lot of solid particles were deposited at the bottom of four pitched-blade impeller stirred tank, circle package impeller can reduce the number of solid particles deposited at the stirred tank bottom, and punched circle package impeller can further improve the homogenous degree of solid particles compared with circle package impeller at the same power consumption. This phenomenon can be explained by the fact that punched circle package impeller can improve the integrated velocity of solid particles in the region between the 
bottom of stirred tank and the lower impeller compared with circle package impeller and four pitched-blade impeller (Figure 17), which was beneficial to the suspension process of solid particles. Meanwhile, punched circle package impeller can generate a series of jet flows, the shear action of the jet flows on the surrounding fluid will increase the velocity gradient, and can enhance the turbulent kinetic energy and turbulent kinetic energy dissipation rate of solid-liquid mixing system on the basis of circle package impeller and four pitched-blade impeller at the constant power consumption (Figures 18 and 19). It indicated that punched circle package impeller can improve the solid particle suspension quality on the basis of circle package impeller and four pitched-blade impeller at the same power consumption.

\section{Conclusions}

Punched circle package impeller was introduced as a novel approach to improve the level of homogeneity in solid particle suspension process. The solid particle suspension characteristics in a stirred tank with four pitched-blade impellers, circle package impellers, and punched circle package impellers were investigated comparatively via computational fluid dynamics simulation. Axial solid concentration profile, solid concentration distribution, cloud height, solid sediment height, just suspension speed, solid integrated velocity, turbulent kinetic energy, and turbulent kinetic energy dissipation rate in the stirred tank were predicted. The effects of impeller speed, power consumption, impeller type, aperture size/ratio, solid particle diameter and liquid viscosity on the solid particle suspension quality were investigated. Results showed that the solid particle suspension quality was improved with an increment in the impeller speed, in term of axial solid concentration profile, solid concentration distribution, and cloud height. Punched circle package impeller could reduce the just suspension speed and improve the level of homogeneity for solid-liquid mixing process on the basis of four pitched-blade impeller and circle package impeller. The optimum aperture ratio and aperture diameter were $11.8 \%$ and $8 \mathrm{~mm}$, respectively, for the solid particles suspension process in this work. Smaller particle diameter resulted in smaller settling velocity and higher solid particle suspension quality. More viscous liquid was easier for sustaining the solid particles in suspension state. Meanwhile, punched circle package impeller can reduce the power consumption compared with four pitched-blade impeller and circle package impeller at the same impeller speed, and enhance the solid integrated velocity, turbulent kinetic energy, and turbulent kinetic energy dissipation rate of solid-liquid mixing system under the constant power consumption, which was beneficial for solid particle suspension process in the stirred tank.

\section{Nomenclature}

\begin{tabular}{ll}
$T$ & stirred tank diameter, $\mathrm{m}$ \\
$H$ & liquid height, $\mathrm{m}$ \\
$W$ & baffle width, $\mathrm{m}$ \\
$R$ & stirred tank radius, $\mathrm{m}$ \\
$Z$ & axial coordinate, $\mathrm{m}$ \\
$r$ & radial coordinate, $\mathrm{m}$ \\
$C_{\mathrm{h}}$ & local solid volume fraction at height of $h$ \\
$C_{\mathrm{avg}}$ & average solid volume fraction \\
$n$ & number of sampling points \\
$d_{\mathrm{p}}$ & particle diameter, $\mu \mathrm{m}$ \\
$U$ & velocity vector, $\mathrm{m} / \mathrm{s}$ \\
$P$ & pressure, Pa \\
$g$ & gravitational acceleration, $\mathrm{m} / \mathrm{s}^{2}$ \\
$C_{\varepsilon 1}, C_{\varepsilon 2}, C_{\mu}$ & parameters in the standard $k-\varepsilon$ model \\
$k$ & turbulent kinetic energy, $\mathrm{m}^{2} / \mathrm{s}^{2}$ \\
$F_{\mathrm{i}}$ & effects of external force, turbulent dispersion force, \\
$R_{\mathrm{ij}}$ & virtual mass force and lift force $(N)$ \\
$I$ & interaction force, $\mathrm{N}$ \\
$C_{\mathrm{D}}$ & unit stress tensor \\
$F_{\mathrm{drag}}$ & drag coefficient \\
$N$ & drag force, $\mathrm{N}$ \\
$P_{\mathrm{w}}$ & impeller speed, $\mathrm{s}^{-1}$ \\
$\rho_{\mathrm{l}}$ & power consumption, W \\
$\rho_{\mathrm{s}}$ & liquid density, kg/m $\mathrm{m}^{3}$ \\
$\rho_{\mathrm{m}}$ & solid density, $\mathrm{kg} / \mathrm{m}^{3}$ \\
$\tau$ & Density, kg/m \\
$\alpha$ & stress-strain tensor \\
$\lambda$ & volume fraction \\
$\varepsilon$ & bulk viscosity \\
$\mu$ & turbulent energy dissipation rate \\
$\mu_{\mathrm{m}}$ & viscosity, Pa s \\
$\mu_{\mathrm{t}, \mathrm{m}}$ & molecular viscosity, Pa s \\
$\sigma_{\mathrm{k}}, \sigma_{\varepsilon}$ & turbulent viscosity, Pa s \\
& $k$ and $\varepsilon$ turbulent Prandtl number \\
& \\
\hline &
\end{tabular}

Acknowledgment: The study was supported by the Scientific Research Projects for High-Level Talents of Chongqing Technology and Business University (1956006), Science and Technology Research Project of Chongqing Education Commission (KJQN201900802), Natural Science Foundation of Chongqing Technology and Business University (1952041), and National Natural Science Foundation of China (21636004). 


\section{References}

Chen, J. G., D. Y. Luan, S. J. Zhou, and S. Y. Chen. 2011. "Numerical Simulation of Solid-Liquid Suspension Performance with a FourPitched-Blade Punched Turbine." Petroleum Chemistry Equipment 40: 29-32.

Dohi, N., T. Takahashi, K. Minekawa, and Y. Kawase. 2004. "Power Consumption and Solid Suspension Performance of Large-Scale Impellers in Gas-Liquid-Solid Three-Phase Stirred Tank Reactors." Chemical Engineering Journal 97: 103-14.

Gu, D. Y., Z. H. Liu, Z. H. Qiu, C. L. Xu, Z. M. Xie, J. Li, C. Y. Tao, and Y. D. Wang. 2017a. "Solid-Liquid Suspension Behavior Intensified by Punched Rigid-Flexible Impeller." CIESC Journal 68: 4556-64.

Gu, D. Y., Z. H. Liu, Z. H. Qiu, J. Li, C. Y. Tao, and Y. D. Wang. 2017b. "Design of Impeller Blades for Efficient Homogeneity of SolidLiquid Suspension in a Stirred Tank Reactor." Advanced Power Technology 28: 2514-3.

Hosseini, S., D. Patel, F. Ein-Mozaffari, and M. Mehrvar. 2010. “Study of Solid-Liquid Mixing in Agitated Tanks Through Computational Fluid Dynamics Modeling.” Industrial \& Engineering Chemistry Research 49: 4426-35.

Ibrahim, S., S. D. Wong, I. F. Baker, Z. Zamzam, M. Sato, and Y. Kato. 2015. "Influence of Geometry and Slurry Properties on Fine Particles Suspension at High Loadings in a Stirred Vessel." Chemical Engineering Research and Design 94: 324-36.

Kasat, G. R., A. R. Khopkar, V. V. Ranade, and A. B. Pandit. 2008. “CFD Simulation of Liquid-Phase Mixing in Solid-Liquid Stirred Reactor." Chemical Engineering Science 63: 3877-85.

Khopkar, A. R., G. R. Kasat, A. B. Pandit, and V. V. Ranade. 2016. "Computational Fluid Dynamics Simulation of the Solid Suspension in a Stirred Slurry Reactor." Industrial \& Engineering Chemistry Research 45: 4416-28.

Klenov, O. P., and A. S. Noskov. 2011. "Solid Dispersion in the Slurry Reactor with Multiple Impellers." Chemical Engineering Journal 177: $75-82$.

Kumaresan, T., and J. B. Joshi. 2006. "Effect of Impeller Design on the Flow Pattern and Mixing in Stirred Tanks." Chemical Engineering Journal 115: 173-93.

Liu, J., Y. Ou, and N. Wang. 1999. "Agitation Characteristics of a New Type Punched Agitator Used in Solid-Liquid System." Journal Si Chuan Union University 3: 48-53.

Liu, Z. H., X. Y. Yang, Z. M. Xie, R. L. Liu, C. Y. Tao, and Y. D. Wang. 2013. "Chaotic Mixing Performance of High-Viscosity Fluid Synergistically Intensified by Flexible Impeller and Floating Particles." CIESC Journal 64: 2794-800.

Liu, B., Z. Xu, F. Fan, and B. Huang. 2018. "Experimental Study on the Solid Suspension Characteristics of Coaxial Mixers.” Chemical Engineering Research and Design 133: 335-46.

Liu, B., Z. Xu, Q. Xiao, and B. Huang. 2019. "Numerical Study on Solid Suspension Characteristics of a Coaxial Mixer in Viscous Systems." Chinese Journal of Chemical Engineering 27: 2325-36.

Ljungqvist, M., and A. Rasmuson. 2001. "Numerical Simulation of the Two-Phase Flow in an Axially Stirred Vessel." Chemical Engineering Research and Design 79: 533-46.

Micheletti, M., L. Nikiforaki, K. C. Lee, and M. Yianneskis. 2003. "Particle Concentration and Mixing Characteristics of ModerateTo-Dense Solid-Liquid Suspensions.” Industrial \& Engineering Chemistry Research 42: 6236-49.
Mishra, P., and F. Ein-Mozaffari. 2017. “Using Computational Fluid Dynamics to Analyze the Performance of the Maxblend Impeller in Solid-Liquid Mixing Operations." International Journal of Multiphase Flow 91: 194-207.

Montante, G., G. Micale, F. Magelli, and A. Brucato. 2001. "Experiments and CFD Predictions of Solid Particle Distribution in a Vessel Agitated with Four Pitched Blade Turbines." Chemical Engineering Research and Design 79: 1005-14.

Nurtono, T., H. Setyawan, A. Altway, and S. Winardi. 2009. “MacroInstability Characteristic in Agitated Tank Based on Flow Visualization Experiment and Large Eddy Simulation.” Chemical Engineering Research and Design 87: 923-42.

Pinelli, D., G. Montante, and F. Magelli. 2004. "Dispersion Coefficients and Settling Velocities of Solids in Slurry Vessels Stirred with Different Types of Multiple Impellers." Chemical Engineering Science 59: 3081-9.

Takahashi, K., and S. Sasaki. 1999. “Complete Drawdown and Dispersion of Floating Solids in Agitated Vessel Equipped with Ordinary Impellers." Journal of Chemical Engineering of Japan 32: 40-44.

Tamburini, A., A. Cipollina, G. Micale, A. Brucato, and M. Ciofalo. 2011. "CFD Simulations of Dense Solid-Liquid Suspensions in Baffled Stirred Tanks: Prediction of Suspension Curves." Chemical Engineering Journal 178: 324-41.

Tamburini, A., A. Cipollina, G. Micale, A. Brucato, and M. Ciofalo. 2012. "CFD Simulations of Dense Solid-Liquid Suspensions in Baffled Stirred Tanks: Prediction of the Minimum Impeller Speed for Complete Suspension." Chemical Engineering Journal 193: 234-55.

Tamburini, A., A. Cipollina, G. Micale, A. Brucato, and M. Ciofalo. 2013. "CFD Simulations of Dense Solid-Liquid Suspensions in Baffled Stirred Tanks: Prediction of Solid Particle Distribution." Chemical Engineering Journal 223: 875-90.

Tervasmaki, P., J. Tiihonen, and H. Ojamo. 2014. "Comparison of Solids Suspension Criteria Based on Electrical Impedance Tomography and Visual Measurements." Chemical Engineering Science 116: 128-35.

Wadnerkar, D., R. P. Utikar, M. O. Tade, and V. K. Pareek. 2012. "CFD Simulation of Solid-Liquid Stirred Tanks.” Advanced Power Technology 23: 445-53.

Wadnerkar, D., M. O. Tade, V. K. Pareek, and R. P. Utikar. 2016. “CFD Simulation of Solid-Liquid Stirred Tanks for Low to Dense Solid Loading Systems." Particuology 29: 16-33.

Wang, S., X. Jiang, R. Wang, W. Xu, S. Yang, Z. Jian, and L. Yang. 2017. "Numerical Simulation of Flow Behavior of Particles in a LiquidSolid Stirred Vessel with Baffles." Advanced Power Technology 28: 1161-624.

Wen, C., and Y. Yu. 1966. "Mechanics of Fluidization.” Chemical Engineering Progress Symposium Series 62: 100-111.

Xu, W. X. 2013. Design of Logarithmic Helicoidal Impeller and Research on Solid-Liquidagitated Flow Field. Jiangshu University, Zhengjiang.

Yang, H., F. Wang, and C. Wang. 2015. "Optimizing Structural Parameters of Punched Impeller." Journal Wuhan Institute Technical 37: 39-43.

Zhao, Q., X. Quan, and Y. Liang. 2007. "Study on a New Orifice Jet Stirrer-Experiments of Axisymmetric Jet in a Solid-Liquid System." Chemical Reaction Engineering and Reactor Technology 23: 512-5. 